\title{
EFEITO DO BENTAZON E BENTAZON + DICHLORPROP NA CULTURA DO ARROZ IRRIGADO E SOBRE AS PLANTAS DANINHAS
}

\author{
C.A.L. dos Santos e L.S.P. Cruz
}

\section{RESUMO}

Foi instalado um experimento de campo, em solo barrento, com a finalidade de se verificar o efeito do bentazon e da mistura de bentazon + dichlorprop sobre o desenvolvimento do arroz em cultura irrigada e sobre o controle das plantas daninhas.

Os tratamentos utilizados foram os seguintes: bentazon á 0,75-1,00 e1,50 kg/ha; bentazon + dichlorprop a $0,80+1,00$ e $1,00+1,40 \mathrm{~kg} / \mathrm{ha}$; propanil a $4,20 \mathrm{~kg} / \mathrm{ha}$ (tratamento padrão); testemunha capinada e testemunha sem capina. Todas as pulverizações foram realizadas em pósemergência.

As plantas daninhas encontradas no experimento foram: capituva - Echinochloa colonum (L) Link, tiririca amarela - Cyperus esculentus L., beldroega - Portulaca oleracea L. e carurú comum Amaranthus viridis L.

Bentazon a 1,00 e $1,50 \mathrm{~kg} / \mathrm{ha}$ e bentazon + dichlorprop a $1,00+1,40 \mathrm{~kg} / \mathrm{ha}$ foram eficientes no controle de $P$. oleracea, $A$. viridis e C. esculentus; já a dose menor de bentazon apresentou bons resultados contra $P$. oleracea e A. viridis, enquanto que a dose menor de bentazon + dichlorprop controlou apenas $P$. oleracea. Propanil, de uma maneira geral, proporcionou eficiente ação sobre as plantas daninhas.

Nas condições em que foi realizado o experimento nenhum dos herbicidas, nas suas respectivas doses, apresentou fitotoxicidade para as plantas de arroz da variedade IAC-435 ou prejudicou a produção da cultura.
Pesquisadores Científicos do Instituto Biológico, Seção de Herbicidas. Caixa Postal 70 - 13.100 Campinas, SP.

Trabalho apresentado na I RETERIESP (Reunião de Técnicos em Rizicul tura do Estado de São Paulo), 1979, Campinas, SP.

Recebido para publicação em 20.3.79.

\section{SUM MARY}

EFFECT OF BENTAZON AND BENTAZON + DICHLORPROP ON IRRIGATED RICE AND WEEDS

Bentazon at $0.75-1.00$ and $1.50 \mathrm{~kg} / \mathrm{ha}$ a.i., bentazon + dichlorprop at $0.80+1.00$ and $1.00+1.40 \mathrm{~kg}$ and propanil at $4.20 \mathrm{~kg}$ were applied in post-emergence on irrigated rice, against the following weeds: Echinochloa colonum (L.) Link, Cy-perus esc-ulentus L., Portulaca oleracea L. and Amaranthus viridis L.

Bentazon at $1.00-1.50 \mathrm{~kg}$ and bentazon + dichlorprop at $1.00+1.40 \mathrm{~kg}$ gave good control of $P$. oleracea, $A$. viridis and C. esculentus; bentazon at $0.75 \mathrm{~kg}$ controlled P. oleracea and A. viridis; bentazon + dichlorprop at $0.80+1.00 \mathrm{~kg}$ only showed effeciency for P. oleracea; propanil, in general, gave good control of the weeds.

The herbicides did not cause injuries to the crop.

\section{INT ROD UÇÃO}

O uso de herbicidas nas culturas em geral vem sendo praticado em grande escala tendendo a crescer ainda mais devido especialmente ao problema de mão de obra. No caso da cultura de arroz, já existem diversos herbicidas 
que podem ser recomendados com segurança, principalmente para o cultivo irrigado, seja em pré-plantio, pré-emergência ou pós-emergência.

Dos vários compostos químicos utilizados no controle de plantas daninhas alguns têm maior ação sobre as monocotiledôneas, outros sobre as dicotiledôneas. Assim é que foi desenvolvido o bentazon, que é um herbicida pós-emergente e que age sobre diversas espécies dicotiledôneas, muito embora seja seletivo para leguminosas e que também apresenta eficiência contra algumas ciperaceas, sendo indicado para a cultura do arroz $(2,3,4,6,7$ e 8$)$.

No presente trabalho bentazon foi utilizado em várias doses, com o objetivo de se verificar sua ação, nas condições do Estado de São Paulo, sobre a cultura do arroz irrigado, bem como sobre as plantas daninhas. Bentazon foi aplicado isoladamente e em mistura com dichlorprop, o qual já vem sendo usado há muito tempo em diversas culturas de gramíneas, tendo ação mais específica sobre as dicotiledôneas (10). A mistura do bentazon com dichlorprop é indicada em alguns países para 0 controle de folhas largas (1).

\section{MATERIAIS E MÉTODOS}

Foi montado um experimento de campo no município de Vargem Grande do Sul, em novembro de 1977, utilizando-se os seguintes tratamentos: bentazon a $0,75-1,00$ e $1,50 \mathrm{~kg} /$ ha; bentazon + dichlorprop a $0,80+1,00$ e $1,00+1,40$ $\mathrm{kg} / \mathrm{ha}$; propanil a $4,20 \mathrm{~kg} / \mathrm{ha}$; testemunha capinada e testemunha sem capina. Propanil foi utilizado como herbicida padrão.

As pulverizações foram realizadas em pós-emergência, aos 20 dias após o plantio, com um pulverizador costal gastando 500 litros de calda por hectare. Antes das aplicações dos herbicidas foi efetuada uma contagem das plantas daninhas em área de $0,50 \mathrm{~m}^{2}$ correspondente à infestação média de cada parce- la. Dez dias após foi praticada uma nova contagem na mesma área a fim de que fosse verificado o efeito dos herbicidas sobre as plantas daninhas. Os dados obtidos das contagens foram transformados em porcentagem, tomando-se como referência a diferença entre a primeira e a segunda contagem. No mesmo dia das pulverizações foi feita a limpeza mecânica das parcelas da testemunha capinada.

Foram feitas observações periódicas sobre possiveis sintomas de fitotoxicidade dos herbicidas nas plantas de arroz.

A variedade de arroz utilizada foi a IAC-435. O delineamento estatístico empregado foi o de blocos ao acaso, com 8 tratamentos repetidos 4 vezes. As parcelas eram constituídas por 5 linhas com $5,00 \mathrm{~m}$ de comprimento, espaçadas de $0,30 \mathrm{~m}$, com área útil de 4,50 m2.

As espécies botânicas presentes no experimento eram: Echinochloa colonum, Cyperus esculentus, Portulaca oleracea e Amaranthus viridis.

A colheita foi realizada em 17 de abril de 1978, nas 3 linhas centrais e no comprimento total de cada parcela.

\section{RESULTADOS E DISCUSSÃO}

No quadro 1 encontram-se os resultados de controle das plantas daninhas. Verifica-se que E. colonum só foi controlado por propanil. C. esculentus teve um bom controle por parte de bentazon a 1,00 e $1,50 \mathrm{~kg} /$ ha, bentazon + dichlorprop a $1,00+1,40 \mathrm{~kg} / \mathrm{ha} \mathrm{e}$ propanil, havendo maior destaque para bentazon a $1,50 \mathrm{~kg} / \mathrm{ha}$. $P$. olerace a foi plenamente combatida por todos os herbicidas nas suas respectivas doses. Com relação a $A$. viridis, somente bentazon + dichlorprop a $0,80+1,00$ $\mathrm{kg} / \mathrm{ha}$ é que não proporcionou bom resultado, havendo grande destaque para os demais tratamentos com herbicidas.

Considerando-se o controle geral, observa-se que os melhores tratamen- 
Quadro 1. Porcentagem de controle de plantas daninhas e produçáo de arroz em casca, em ensaio de herbicidas em pós-emergència em arroz irrigado em Vargem Grande do Sul-SP.

Tratamento: 19 de dezembro de 1977; Contagem das plantas daninhas: 29 de dezembro de 1977 Colheita: 17 de abril de 1978

\begin{tabular}{|c|c|c|c|c|c|c|c|}
\hline Herbicidas & $\begin{array}{l}\text { Ingredien- } \\
\text { te ativo } \\
(\mathrm{kg} / \mathrm{ha})\end{array}$ & $\begin{array}{l}\text { Echino- } \\
\text { chloa co- } \\
\text { lonum }\end{array}$ & $\begin{array}{l}\text { Cyperus } \\
\text { esculentus }\end{array}$ & $\begin{array}{c}\text { Portulaca } \\
\text { oleracea }\end{array}$ & $\begin{array}{c}\text { Amaran- } \\
\text { thus viri- } \\
\text { dis }\end{array}$ & $\begin{array}{l}\text { Controle } \\
\text { geral }\end{array}$ & $\begin{array}{l}\text { Produção } \\
\text { (kg/ha) }\end{array}$ \\
\hline Bentazon & 0,75 & 0,0 & 61,5 & 95,6 & 90,0 & 68,4 & 5.166 \\
\hline Bentazon & 1,00 & 0,0 & 82,1 & 100 & 100 & 75,8 & 4.944 \\
\hline Bentazon & 1,50 & 0,0 & 93,5 & 98,9 & 100 & 93,6 & 5.055 \\
\hline Bentazon & 0,80 & & & & & & \\
\hline+ & + & 0,0 & 0,0 & 95,0 & 60,0 & 22,9 & 5.000 \\
\hline Dichlor prop & 1,00 & & & & & & \\
\hline Bentazon & 1,00 & & & & & & \\
\hline & + & 32,0 & 85,7 & 100 & 100 & 77,2 & 4.888 \\
\hline Dichlorprop & 1,40 & & & & & & \\
\hline Propanil & 4,20 & 94,5 & 88,8 & 100 & 100 & 93,0 & 4.944 \\
\hline $\begin{array}{l}\text { Testemunha } \\
\text { capinada }\end{array}$ & $\begin{array}{l}\text { (n. } .^{\circ} \text { de } \\
\text { plantas da- } \\
\text { ninhas) }\end{array}$ & 348 & 248 & 168 & 56 & 820 & 5.000 \\
\hline \multirow{3}{*}{$\begin{array}{l}\text { Testemunha não } \\
\text { capinada }\end{array}$} & $\left(\mathrm{n} .^{\circ}\right.$ de plan & & & & & & \\
\hline & $\begin{array}{l}\text { tas dani- } \\
\text { nhas) }\end{array}$ & 312 & 301 & 106 & 72 & 791 & 3.611 \\
\hline & & & & & & $\begin{array}{l}\text { C.V. } \\
\text { F. }\end{array}$ & $\begin{array}{l}11 \% \\
4,00 * *\end{array}$ \\
\hline
\end{tabular}


tratamentos, quando comparados com a testemunha capinada (quadro 1). A testemunha não capinada apresentou uma produção inferior, cerca de 38\% menos que a testemunha capinada. A análise estatística dos dados de produção pelo método da variância, revelou diferença altamente significativa entre a testemunha não capinada e os demais tratamentos. O coeficiente de variação foi de $11 \%$.

\section{LITERA TURA CITADA}

1. British Crop Protection Council. Pesticides. London, Hubert Martin, 1977. 181p.

2. Daniel, J.W. Basagran for dayflower control in rice. In: Proc. 27th Annual Meet. South. Weed. Sci. Soc. USA, 1975, p.121.

3. Ghosh, A.K.; Chowdhury Roy, S. e Sarkar, P.A. Weed control in direct seeded flooded rice. Pesticides 8(3): 29-31, 1974. (Weed Abstract 24(4): 63, 1975).

4. Gupta, B.B. e Soodan, M.S. A comparative study on the use of Basagran (bentazon) and
Stam F-34 (propanil) in transplanted rice. Pesticides 9(5): 21-22, 1975. (Weed Abstract 25(4): 101, 1976).

5. Hack, R. El cultivo del arroz en Egipto y la solución del problema del control de las malas hierbas. Reportes Agrícolas BASF 3:34, 1977.

6. Koston, P.; Luib, M. e Weerd, J.C. Vande. Experiences with bentazon for weed control in rice and soya beans. In: $8^{\text {th }}$ Int. Cong. of Plant. Prot., Reports and Informations, Section 3. Chemical Control, Moscow, 1975, p.420-429. (Weed Abstracts 25(11): 363, 1976).

7. Luib, M. e Weerd, J.C. Vande. New results with bentazon in the rice growing areas of Europe and the Americas (Sown rice). In: Proc. $5^{\text {th }}$ Asian Pac. Weed Sci. Soc. Conf., Tokyo, 1976, p.256-259.

8. Luib, M. e Weerd, J.C. Vande. New results with bentazon and bentazon combinations in rice. In: Proc. 12th Britsh Weed Con. Conf., London, 1974. p.151-156.

9. Nine, A.; Hino, N. e Ueda, M. Studies on the herbicidal properties of bentazon under paddy field conditions. I - Environmental and cultural factors influencing herbicidal activity. Weed Research, 17: 64-70, 1974.

. . Fryer, J.D. and Makepeace, R.J. Weed Control Handbook. 6th edition, London, 1977. 101p. 